\title{
Efficacy, Safety and Tolerability of High dose Valsartan Hydrochloride in Essential Hypertension
}

\author{
MA Zaman \\ Department of Cardiology, Bangladesh Medical College Hospital, Dhaka, Bangladesh
}

\begin{abstract}
Key word:

Background: Studies across the world have demonstrated the efficacy of valsartan in lowering blood Valsartan, pressure in a variety of patient populations, several of them investigated higher doses of the drug. This study focuses on revealing safety and efficacy of valsartan at higher doses in Bangladeshi population. High dose, AntiCurrent study is planned to evaluate the efficacy, safety and tolerability of daily dose of Valsartan 160 or hypertensive, Safety, efficacy and $320 \mathrm{mg}$ in the treatment of essential hypertension.

Method: This is a multi-center, open-label, observational, non-comparative, clinical decision based titration, involving about 31 centers in Bangladesh. A total of 334 newly diagnosed adult patients with essential hypertension received valsartan at a dose of $160 \mathrm{mg}$ or $320 \mathrm{mg}$ as deemed necessary by physician were included to allow for an assessment of efficacy, safety and tolerability. The total duration of treatment with valsartan was 16 weeks. Primary parameter for efficacy was percentage responders to valsartan at 16 weeks, reduction in Mean sitting systolic blood pressure (MSSBP) and Mean sitting Diastolic blood pressure $M S D B P$, control rate (\% patients) achieving $S B P<140 \mathrm{mmHg}$ and $D B P<90 \mathrm{mmHg}$ at end point and Global assessment of efficacy and tolerability to valsartan treatment by the physician and patient.

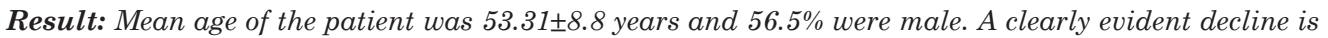
evident in mean Systolic BP and diastolic BP over the study duration. Average reduction of $30.4 \pm 17.4$ $\mathrm{mmHg}$ was seen in systolic BP, $18.4 \pm 11.2 \mathrm{mmHg}$ in diastolic BP and $3.5 \pm 3.1 /$ minute in heart rate. The reduction was highly significant in both systolic BP and diastolic BP and heart rate as well $(P<.001)$. At 16 weeks only $3.4 \%$ were found to be refractory to the treatment. Global assessment of safety and efficacy was assessed on four point scale, around $30.2 \%$ of the physician rated the efficacy as excellent, around $56 \%$ rated as very good and $13.8 \%$ rated as good. Tolerability of the treatment was also assessed based on the opinion of the patient and physician concerned on four point scale. Around $34.1 \%$ of the physician rated the tolerability as excellent, around $49.7 \%$ rated as very good and $16.2 \%$ rated as good.

Conclusion: Sixteen week treatment with valsartan at $160 \mathrm{mg}$ daily or $320 \mathrm{mg}$ daily is an effective treatment for patients with essential hypertension. The drug is found to be well tolerated with minimal adverse event during the course of treatment.
\end{abstract}

(Cardiovasc. j. 2013; 5(2): 182-189)

\section{Introduction:}

Angiotensin II is a potent vasoconstrictor and also stimulates the release of aldosterone, which causes a further rise in blood pressure. ${ }^{1}$ Valsartan is an angiotensin II receptor blocker for the treatment of hypertension, heart failure, and left ventricular failure or left ventricular dysfunction postmyocardial infarction. Its effects primarily result from selective blockade of the angiotensin type I receptor in vascular smooth muscle and adrenal gland. ${ }^{2}$ Valsartan effectively reduces systolic blood pressure (SBP) and diastolic blood pressure (DBP). ${ }^{3}$ Given its effects on angiotensin blockade, valsartan may also reduce proteinuria and have other beneficial effects in patients with underlying kidney disease. ${ }^{4}$ For these reasons, valsartan is an attractive drug for use in hypertension. Valsartan is a highly selective, orally available antagonist of the angiotensin Type $1\left(\mathrm{AT}_{1}\right)$ receptor. It is indicated for treatment of mild to moderate essential hypertension. Experimental studies have confirmed the abolition or attenuation of angiotensin II (AII)-related effects, such as

Address of Correspondence : Prof. MA Zaman, Department of Cardiology, Bangladesh Medical College Hospital, Dhaka, Bangladesh 
vasoconstriction, cell growth promotion and aldosterone release. In humans, valsartan is rapidly absorbed with maximal plasma concentrations occurring 1-2 h after oral administration. The elimination half-life comes to about $7-8 \mathrm{~h}$, valsartan is metabolised to a negligible extent and most of the drug is excreted via the faeces. There is no dose adjustment required for patients with a creatinine clearance $>10 \mathrm{ml} / \mathrm{min}$.

In comparison to other antihypertensive drugs valsartan therapy leads to similar blood pressure reductions, while exhibiting a favourable tolerability profile. Preliminary studies suggest beneficial effects in patients with hypertensive end-organ damage such as renal disease and left ventricular hypertrophy. Furthermore, the drug is evaluated for its efficacy in heart failure and patients' postmyocardial infarction. ${ }^{5}$ The efficacy, tolerability and safety of valsartan have been demonstrated in large-scale studies conducted in difference population in hypertension, heart failure (HF) and post-myocardial infarction (MI). Many studies have demonstrated the efficacy of valsartan in lowering blood pressure in a variety of patient populations, several of them are investigated higher doses of the drug. This study focuses on reveling safety and efficacy of valsartan at higher doses in Bangladeshi population. From the data available now, daily dose of Valsartan $160 \mathrm{mg}$ consistently provides greater BP-lowering efficacy than the $80-\mathrm{mg}$ dose. Current study is planned to further evaluate the efficacy, safety and tolerability of daily dose of Valsartan 160 and $320 \mathrm{mg}$ in the treatment of essential hypertension under normal practice conditions.

\section{Methodology}

\section{Patients and materials}

This is a multi-center, open-label, observational, non-comparative, clinical decision based titration, involving about 31 centers in Bangladesh. A total of 334 newly diagnosed adult patients with Stage I (SBP 140-159 mmHg/DBP $90-99 \mathrm{mmHg}$ ) or Stage II ( $\mathrm{SBP}>160 \mathrm{mmHg} /$ DBP $>100 \mathrm{mmHg}$ ) essential hypertension received valsartan as determined by their physician were included to allow for an assessment of efficacy, safety and tollarability. Pregnant or lactating mother, patient with severe medical condition(s) that in the view of the Investigator prohibits participation in the study and known Hypersensitivity to valsartan or any of the components in the formulation are excluded. The total duration of treatment with valsartan was 16 weeks. At week 0, patient received valsartan at a dose of $160 \mathrm{mg}$ or 320 $\mathrm{mg}$ as deemed necessary by physician. At Visit 2 , the Investigator decided the dose of valsartan which the patient continued for the remainder of the study, based on the blood pressure control. If the blood pressure was not controlled (SDBP $\geq 90 \mathrm{~mm} \mathrm{Hg}$ and/or $\mathrm{SSBP} \geq 140 \mathrm{mmHg}$ ) the Investigator titrated the dosage of valsartan to $320 \mathrm{mg}$. If the blood pressure was controlled (SDBP $<90 \mathrm{mmHg}$ and/or SSBP $<140 \mathrm{mmHg}$ ), the dose of valsartan was also titrated to 320 $\mathrm{mg}$ in some patients, based on investigator's clinical judgment for a further reduction (better control) in blood pressure. This dose was then continued for the remainder of the study period. In general concomitant therapy was allowed with proper documentation however, Other antihypertensive agents (including diuretics), that might interfere with evaluation of efficacy and tolerability, was avoided as far as possible, and if used, the details were recorded.

\section{Outcome assessment}

Patients were assessed five times over the study period of 16 weeks. At the commencement baseline parameters as well concomitant treatment status was assessed along with the enrollment criteria. In the following three assessments in Week 4, 8, and 12 treatment response were assessed along with history of concomitant Treatment and adverse event. After completion of $16^{\text {th }}$ week valsartan therapy in addition to the measurement taken in the previous assessments a global assessment of treatment outcome was done on a 4-point scale by the investigator and the patient.

Primary parameter for efficacy was percentage responders to valsartan at 16 weeks, defined as 
$\mathrm{SBP}<140 \mathrm{mmHg}$ and/or DBP $<90 \mathrm{mmHg}$ or a reduction $>10 \mathrm{mmHg}$ for $\mathrm{DBP}$ and/or $>20 \mathrm{mmHg}$ SBP versus baseline values. Reduction in MSSBP and MSDBP, Control rate (\% patients) achieving SBP $<140 \mathrm{mmHg}$ and DBP $<90 \mathrm{mmHg}$ at end point and Global assessment of efficacy and tolerability to valsartan treatment by the physician and patient. Tolerability/safety assessments consisted of monitoring and recording all adverse events and serious adverse events. Global assessment of the physicians and patients evaluation about the efficacy and tolerability was done on a 4 -point scale. Data collection activity was conducted abiding by the principles of Good Clinical Practice, the declaration of Helsinki. To protect the confidentiality of data and to preserve patient anonymity, each subject was assigned with an unique indentifying number.

\section{Data analysis}

This is a descriptive intention to treat (ITT) analysis. Baseline characteristics were described by summary statistics. Assessment of efficacy was done based on the number of the patients with a controlled diastolic pressure and systolic pressure. The efficacy analysis of continuous variables was done descriptively by presenting summary statistics and confidence intervals. The safety and tolerance evaluation was done based on the frequency and nature of reported adverse events. Paired t test was used to assess mean BP between the measurement at baseline and end line.

\section{Result}

\section{Patient characteristics}

Out of 334 Adult hypertensive patients $7.2 \%$ were aged less than 40 years, $23.1 \%$ were aged between $40-49$ years, $41.0 \%$ were aged between $50-59$ years and $28.7 \%$ were aged above 60 years. Mean age of the patient was
$53.31 \pm 8.8$ years. Among them $56.5 \%$ were male and $43.4 \%$ were female. Around one percent of them had BMI $<18.5 \mathrm{~kg} / \mathrm{m}^{2}, 47.3 \%$ had BMI between 18.5 to $25 \mathrm{~kg} / \mathrm{m}^{2}$ and $51.8 \%$ had BMI over $25 \mathrm{~kg} / \mathrm{m}^{2}$.

Table-I

Age sex and BMI of patients of the study population

\begin{tabular}{lcc}
\hline & Frequency & Percent \\
\hline Age & & \\
$\quad<40$ years & 24 & 7.2 \\
40 - 49 years & 77 & 23.1 \\
$\quad$ 50 - 59 years & 137 & 41.0 \\
$\quad>=60$ years & 96 & 28.7 \\
Sex & & \\
$\quad$ Male & 189 & 56.6 \\
$\quad$ Female & 145 & 43.4 \\
BMI & & \\
$\quad<18.5$ & 3 & 0.9 \\
$\quad$ 18.5 - 25 & 158 & 47.3 \\
$\quad>25$ & 173 & 51.8 \\
\hline
\end{tabular}

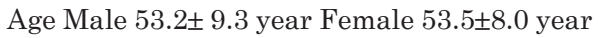

\section{Treatment profile}

Among the study subjects medication were changed at $2^{\text {nd }}$ visit in $4.5 \%$. The percentage was $2.4 \%, 1.8 \%$ and $2.4 \%$ in next three successive visits respectively. New concomitant treatment was started in $3.6 \%$ cases at $2^{\text {nd }}$ visit and $1.3 \%$ in $3^{\text {rd }}$ visit and in $1.2 \%$ at $4^{\text {th }}$ visit. Adverse event was reported in three cases each $(0.9 \%)$ at $2^{\text {nd }}$, $3^{\text {rd }}$ visit and $4^{\text {th }}$ visit and in 2 cases $(2.4 \%)$ at $5^{\text {th }}$ visit. Total adverse event occurred in 11 (3.3\%) patients. At the commencement of the study $1.2 \%$ was prescribed with valsartan $320 \mathrm{mg}$ rest received Valsartan $160 \mathrm{mg}$. At $2^{\text {nd }}$ visit $3.9 \%$ were given with Valsartan $320 \mathrm{mg}$. At $3^{\text {rd }}, 4^{\text {th }}$ and $5^{\text {th }}$ visit patient requiring Valsartan $320 \mathrm{mg}$ rose to $6.3 \%, 8.1 \%$ and $10.5 \%$ respectively. (Table II)

Table-II

Treatment profile of the study population

\begin{tabular}{lccccc}
\hline Treatment profile & Visit 1 & Visit 2 & Visit 3 & Visit 4 & Visit 5 \\
& $(\mathrm{N}=334)$ & $(\mathrm{N}=334)$ & $(\mathrm{N}=334)$ & $(\mathrm{N}=334)$ & $(\mathrm{N}=334)$ \\
\hline Dose: 160mg once daily & $330(98.8)$ & $321(96.1)$ & $313(93.7)$ & $307(91.9)$ & $299(89.5)$ \\
Dose: 320 mg once daily & $4(1.2)$ & $13(3.9)$ & $21(6.3)$ & $27(8.1)$ & $35(10.5)$ \\
Change in medication & - & $15(4.5)$ & $8(2.4)$ & $6(1.8)$ & $8(2.4)$ \\
Concomitant treatment & - & $12(3.6)$ & $4(1.3)$ & $4(1.2)$ & - \\
Adverse event & - & $03(0.9)$ & $3(0.9)$ & $3(0.9)$ & $2(0.6)$ \\
\hline
\end{tabular}

*Figures in parenthesis denotes percentage 
Assessment of $\mathrm{BP}$ reduction

A clearly evident decline is evident in mean Systolic BP and diastolic BP over the study duration (Figure 1). The fall of mean Systolic BP is steeper than that of Diastolic BP. Control rate is considered as percentage of patients with SBP $<140 \mathrm{mmHg}$ and DBP $<90 \mathrm{mmHg}$ at all 4 visits. At 2 nd visit $19.8 \%$ had their BP controlled, at $3 \mathrm{rd}$ visit the percentage is $36.5 \%$ at 4 th visit the percentage is $60.2 \%$ and at 5 th visit $81.7 \%$ had their BP controlled (Figure 2). Change in $\mathrm{BP}$ and Heart rate was assessed at the end of the treatment in comparison to baseline parameters through paired t test. Average reduction of $30.4 \pm 17.4 \mathrm{mmHg}$ was seen in systolic BP, $18.4 \pm 11.2 \mathrm{mmHg}$ in diastolic BP and $3.5 \pm 3.1 /$ minute in heart rate. The reduction was highly significant in both systolic BP and diastolic $\mathrm{BP}$ and heart rate as well $(\mathrm{P}<.001)$. At 16 weeks only $3.4 \%$ were found to be refractory to the treatment. (Table III)

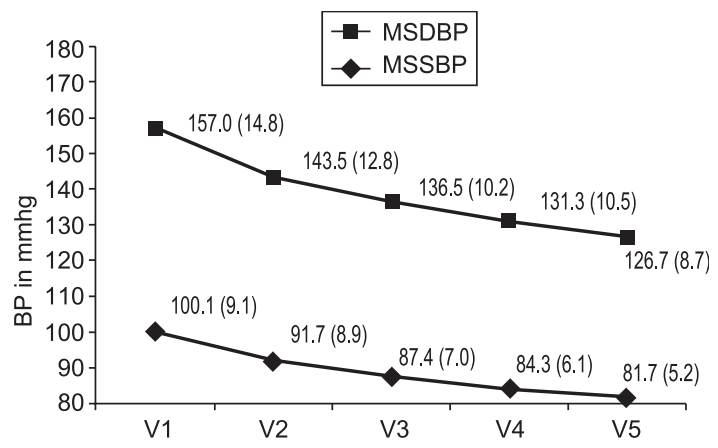

Fig.-1: Trend of blood pressure reduction
Global assessment of safety and efficacy

Efficacy of the treatment was assessed based primarily on the opinion of the patient and physician concerned on four point scale. Around $30.2 \%$ of the physician rated the efficacy as excellent, around $56 \%$ rated as very good and $13.8 \%$ rated as good. Regarding patient's opinion around $26.9 \%$ rated the efficacy as excellent, around $57.8 \%$ rated as very good, around $15.3 \%$ rated as good. Tolerability of the treatment was also assessed based on the opinion of the patient and physician concerned on four point scale. Around $34.1 \%$ of the physician rated the efficacy as excellent, around $49.7 \%$ rated as very good and $16.2 \%$ rated as good. Regarding patient's opinion around $36.8 \%$ rated the tolerability as excellent, around $47 \%$ rated as very good, around $16.2 \%$ rated as good. (Table IV)

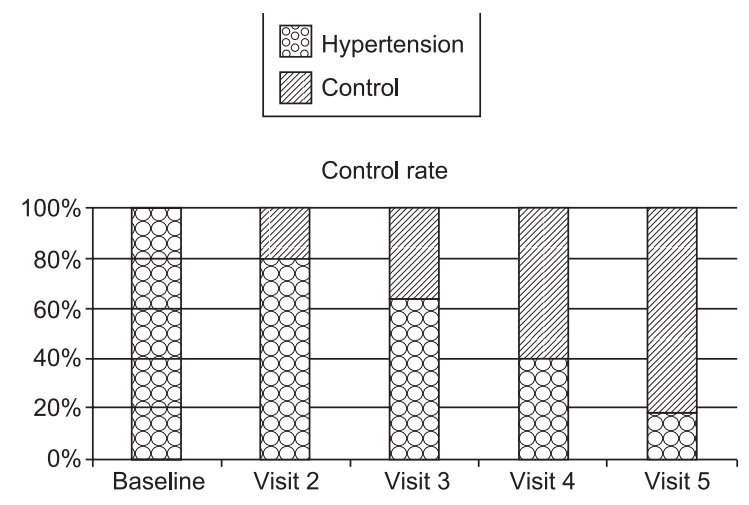

Fig.-2: Trend of control rate at each visit.

Table III

Reduction of BP after treatment

\begin{tabular}{lcccccc}
\hline Variables & \multicolumn{2}{c}{ Assessment time } & & \multicolumn{2}{c}{ Paired mean difference } & \\
\cline { 2 - 3 } & Baseline & End line & & difference & t value & P value \\
\hline SBP $(\mathrm{N}=334)$ & $157.0 \pm 14.8$ & $126.7 \pm 8.7$ & & $30.4 \pm 17.4$ & 33.2 & $.001^{*}$ \\
DBP $(\mathrm{N}=334)$ & $100.1 \pm 9.9$ & $81.7 \pm 5.4$ & & $18.4 \pm 11.2$ & 31.6 & $.001^{*}$ \\
Heart rate $(\mathrm{N}=334)$ & $77.8 \pm 5.4$ & $74.3 \pm 5.2$ & & $3.5 \pm 3.1$ & 1.8 & $.001^{*}$ \\
\hline
\end{tabular}

*Percentage responder at the end of the trial $96.6 \%$ 
Table IV

Global assessment of efficacy and tolerability

\begin{tabular}{|c|c|c|c|c|c|c|c|c|}
\hline \multirow{3}{*}{ Assessmentscal } & \multicolumn{4}{|c|}{ Assessment of efficacy } & \multicolumn{4}{|c|}{ Assessment of tolerability } \\
\hline & \multicolumn{2}{|c|}{$\begin{array}{l}\text { Physician's } \\
\text { assessment }\end{array}$} & \multicolumn{2}{|c|}{$\begin{array}{l}\text { Patient's } \\
\text { assessment }\end{array}$} & \multicolumn{2}{|c|}{$\begin{array}{l}\text { Physician's } \\
\text { assessment }\end{array}$} & \multicolumn{2}{|c|}{$\begin{array}{c}\text { Patient's } \\
\text { assessment }\end{array}$} \\
\hline & Frequency & Percent & Frequency & Percent & Frequency & Percent & Frequency & Percent \\
\hline Excellent & 101 & 30.2 & 90 & 26.9 & 114 & 34.1 & 123 & 36.8 \\
\hline Very Good & 187 & 56.0 & 193 & 57.8 & 166 & 49.7 & 157 & 47.0 \\
\hline Good & 046 & 13.8 & 051 & 15.3 & 054 & 16.2 & 054 & 16.2 \\
\hline Total & 334 & 100.0 & 334 & 100.0 & 334 & 100.0 & 334 & 100.0 \\
\hline
\end{tabular}

\section{Discussion:}

Hypertension is one of the most important preventable causes of premature death worldwide and it is one of the three most important risk factors for cardiovascular disease and is a major burden for global health. ${ }^{6-8}$ Prescribers are faced with many data from an expanding pool of large studies, yet, beyond the sheer time needed to update the evidence base, it can be difficult to translate and synthesize results into rational treatment decisions for individual patients. ${ }^{9,10}$ The benefits of antihypertensive drugs have been confirmed by the largest evidence base from clinical trials in medicine. Many classes of drugs are available for treatment, and debate has raged about whether the benefits of treatment are purely a function of the quality of blood pressure control or whether the type of drug used might also be a powerful determinant of outcome. A metaanalysis of trials of treatment for hypertension with the newer drugs found that ACE inhibitors and calcium channel blockers were likely to reduce cardiovascular morbidity and mortality by the same order of magnitude as â blockers or thiazides, ${ }^{11}$ but such analyses have insufficient statistical power to detect cause specific outcomes with regard to specific drugs.

The renin angiotensin system (RAS) is a key element in the regulation of blood pressure as well as in electrolyte and fluid homeostasis. The active hormone of the RAS is angiotensin II, which is formed from angiotensin I by ACE. Angiotensin II binds to specific receptors which are located in the cell membranes of various tissues. The receptor subtype AT1 is responsible for all the known actions of angiotensin II. Angiotensin II has a wide variety of physiological effects, principally those involved either directly or indirectly, in the regulation of blood pressure (BP). As a potent vasoconstrictor, angiotensin II exerts a direct pressor response. In addition it promotes sodium retention and stimulation of aldosterone secretion, and also stimulates thirst and release of antidiuretic hormone.

The use of ARB for first-line therapy for essential hypertension is well documented. ${ }^{12}$ Valsartan, an angiotensin II receptor blocker with selectivity for the type I receptor subtype, is an established drug for the treatment of essential hypertension. It blocks the action of Angiotensin II irrespective of its origin. ${ }^{13}$ According to Black et al, ${ }^{14}$ in hypertension, valsartan exhibits dose-dependent efficacy in reducing both systolic and diastolic BP over the once-daily dose range of 80-320 mg; doses as high as $640 \mathrm{mg} /$ day have been studied and found to be efficacious and safe. They reported that the magnitude of the BP lowering effect is comparable with that demonstrated with angiotensin-converting enzyme (ACE) inhibitors; however, they reported valsartan as more favorable and tolerable, with a significantly lower incidence of cough and only rare reports of angio-oedema.

Current study focused on the use of the high dose of valsartan in the treatment of essential hypertension with documented endpoint benefit in Bangladeshi population. The study only restricted to native patients with Stage I or Stage 
II essential hypertension. The study used dose regimen of $160 \mathrm{mg}$ and $320 \mathrm{mg}$. As the efficacy of the drug under study has already been documented in numerous clinical trials in different population, the primary goal of our current effort is to validate the treatment modality in Bangladeshi population. In the present study at the commencement $98.8 \%$ received valsartan 160 mg. Increment in dose, although minimum, demonstrates a relative under response or non response with the initial therapy, however leaves the ground for upward titration for achieving the target BP. These allows physician to minimize untoward effect exerted by administration of higher dose of single drug. At successive visits $3.9 \%, 6.3 \%, 8.1 \%$ and $10.5 \%$ received higher doses (320 mg) of valsartan.

In the study concomitant treatment for comorbidity or other conditions were allowed and additional concomitant treatment was added where warranted which have no potential for alter the anti-hypertensive activity. New concomitant treatment was started in $3.6 \%$ cases at $2^{\text {nd }}$ visit and $1.3 \%$ in $3^{\text {rd }}$ visit and in $1.2 \%$ at $4^{\text {th }}$ visit.

One of the major outcome parameter set for the study was the percentage of participant having $\mathrm{BP}$ controlled that is a $\mathrm{SBP}<140 \mathrm{mmHg}$ and DBP $<90 \mathrm{mmHg}$ or a reduction $>10 \mathrm{mmHg}$ for DBP and/or >20 mmHg SBP versus baseline values at 16 weeks. Percentage control at the end of the trial was $96.6 \%$, which is quite high for response of a treatment regimen. Besides, Reduction in mean SBP and mean DBP was also assessed as efficacy parameter. A clearly evident decline is evident in mean systolic and diastolic BP. Reduction in mean systolic BP, diastolic BP and heart rate $(\mathrm{P}<.001)$ was evident through paired comparison from baseline to end of the study. Average reduction of $30.4 \pm 17.4 \mathrm{mmHg}$ was seen in systolic BP and 18.4 $\pm 11.2 \mathrm{mmHg}$ in diastolic BP.

Efficacy of the treatment was also assessed based on the opinion of the patient and physician concerned on four point assessment scale. A potential limitation embedded in the design that might hinder the study goal was that for safety data, as we had to depend on the turnout of patient at final follow-up. However, in the current study out of 334 participants no attrition was occurred. Around $30.2 \%$ of the physician rated the efficacy as excellent, around 56\% rated as very good and $13.8 \%$ rated as good. Regarding patient's opinion around $26.9 \%$ rated the efficacy as excellent, around $57.8 \%$ rated as very good, around $15.3 \%$ rated as good. Regarding tolerability around $34.1 \%$ of the physician rated the efficacy as excellent, around $49.7 \%$ rated as very good and $16.2 \%$ rated as good. Regarding patient's opinion around $36.8 \%$ rated the tolerability as excellent, around $47 \%$ rated as very good, around $16.2 \%$ rated as good. Neither the patient nor the physician rated the efficacy or safety as poor.

According to the data of current study a large proportion of patients benefit from the high dose treatment of Valsartan. Considering the overall treatment effect, as many as $96.6 \%$ of patients showed a response to the treatment. All the three parameter used for efficacy assessment namely, mean BP reduction, percentage control and satisfaction by both physician and patients confirms the efficacy of valsartan as effective antihypertensive. ARBs are generally very well tolerated. The ELITE II study of 3,152 patients aged over 60 years with heart failure showed that patients taking ARB were significantly less likely to discontinue treatment because of adverse effects, ${ }^{15}$ With an asymptomatic condition such as hypertension, long-term compliance can be a problem and side effects have been shown to lead to non-compliance, or to under-treatment with suboptimal doses. ${ }^{16}$ Hypertensive patients tend to be elderly and often have other medical conditions. It is therefore important that long-term treatment with anti-hypertensive drugs do not interact with other medications. ${ }^{17}$

Safety and tolerability assessments focused on monitoring and recording of all adverse events and serious adverse events. At final follow-up, in addition to repetition of the baseline measurements and examinations, data on safety of the drug was collected by inquiring and 
recording all adverse events or serious adverse events. Any untoward event in a patient or revealed through clinical investigation found in patient during the study period which may or may not have a causal relationship with given treatment was recorded and reported by participating physician. Total adverse event occurred in $11(3.3 \%)$ patients. Which is quite low for the treatment of hypertension. Consistent with its angiotensin receptor-blocking effects, valsartan also reduces circulating levels of biochemical markers that are associated with angiotensin II-mediated endothelial dysfunction and Cardio Vascular risk. In clinical trials, adverse events during valsartan treatment were similar to those occurring with placebo.

Study by Oparil et al compared the efficacy and safety of valsartan $320 \mathrm{mg}$ with placebo in the treatment of patients with essential hypertension and reported significant reductions in both MSDBP and MSSBP at end point compared with placebo. There were no clinically or statistically significant changes in laboratory values during treatment as well as no notable side effect. They concluded that valsartan is both effective and safe in reducing blood pressure in adults with essential hypertension. ${ }^{18}$ Schaefer et al also demonstrated a good tolerability of the drug even in children with hypertension. ${ }^{19}$

Our study substantiate similar standpoint to the safety and efficacy of Valsartan at higher doses reveled in other population. Current study upholds the use of the drug at higher dose effective and safe antihypertensive treatment modality. Current study is a prospective observational study, neither randomized nor blinded, which to some extent limits credibility of the findings. However, the intent of the researcher was to assess the safety and efficacy of the treatment modality in our population which was already done by large, well designed and well powered studies in wide range of population and settings. Further investigation could preferably be done with better study design for even stronger evidences.

\section{Conclusion:}

16 week treatment with valsartan at $160 \mathrm{mg}$ daily or $320 \mathrm{mg}$ daily is an effective treatment for patients with essential hypertension. The drug is found to be well tolerated with minimal adverse event during the course of treatment.

\section{Acknowledgement:}

The study has received an unconditional grant and support from, Novartis Pharmaceuticals Bangladesh. The interventional drug for the study used in the study was Diovan ${ }^{\circledR}$ tablet containing $160 \mathrm{mg}$ or $320 \mathrm{mg}$ Valsartan is a registered product of Novartis.

\section{Study Group:}

Prof. MA Zaman, Prof. A.K.M Anwarullah, Prof M. N. Nag, Prof. Mian Mashud, Prof Dr. Md. Shahabuddin Khan, Dr. Abu Azam, Dr. Asia Khanam, Dr. Md. Nazrul Islam, Dr. M Mahabubur Rahman, Dr. Kazi Mohibur Rahman, Dr. M. Muhibur Rahman, Dr. Nabiul Hassan Rana, Prof. Dr. Shakwat Hossain, Dr. Md. Anisur Rahman, Dr. K.H. Haq, Dr. Tarikul Islam, Dr. G.C. Dhar, Dr. Nur M. Abdal, Dr.Md.Mahbubur Rahman, Dr.M. Rezaul Karim, Dr. Sukanta Aich, Dr. Md. Ibrahim Chowdhury, Dr. Shafiul Azam, Dr. M. A. Kashem, Dr. Shahabul Huda Chowdhury, Dr. S.U. Kumer Uttam, Dr. Shah Jamal Hossain, Prof. Mrinal Kanti Das, Dr. Moazzem Hossain, Dr. M.R. Khan, Dr. Jayanta Kumer Podder.

\section{Reference:}

1. Beevers G, Lip GYH, O'Brien E. The pathophysiology of hypertension. BMJ 2001;322: 912-916.

2. Novartis Pharmaceuticals Corporation. DIOVAN ${ }^{\circledR}$ Prescribing Information. East Hanover, NJ: Novartis Pharmaceuticals Corporation; revised November 2007.

3. Markham A, Goa KL. Valsartan. A review of its pharmacology and therapeutic use in essential hypertension. Drugs 1997; 54: 299-311.

4. Chrysant SG, Chrysant GS. Clinical experience with angiotensin receptor blockers with particular reference to valsartan. J Clin Hypertens (Greenwich) 2004; 6: $445-451$.

5. Liu PP, Maggioni A, Velazquez EJ. Use of valsartan in post-myocardial infarction and heart failure patients. J Renin Angiotension Aldosteron Synt. 2006; 7(1): 19-22.

6. Ezzati M, Lopez AD, Rodgers A, Vander Hoom S, Murray CJ. Selected major risk factors and global and regional burden of disease. Lancet 2002;360:1347-1360.

7. He FJ, MacGregor GA. Cost of poor blood pressure control in the UK: 62,000 unnecessary deaths per year. J Hum Hypertens 2003; 17:455-457.

8. Ezzati M, Lopez AD, Rodgers A, Vander Hoorn S, Murray CJL. Selected major risk factors and global and regional burden of disease. Lancet 2002;360:1347-1360. 
9. Appel LJ. The verdict from ALLHAT - thiazide diuretics are the preferred initial therapy for hypertension. JAMA 2002;288:3039-3042.

10. Williams B. Drug treatment of hypertension. BMJ 2003;326:61-62.

11. Collaboration Blood Pressure Lowering Treatment Trialists. Effects of angiotensin converting enzyme inhibitors, calcium antagonists and other blood pressure lowering drugs on mortality and major cardiovascular morbidity. Lancet 2000;356:1955-1964.

12. Joint National Committee on Prevention, Detection, Evaluation, and Treatment of HIgh Blood Pressure. The sixth report of the Joint National Committee on prevention, detection, evaluation, and treatment of high blood pressure. Arch Intern Med 1997; 157: 2413-2446.

13. Markham A, Goa KL. Valsartan: a review of its pharmacology and therapeutic use in essential hypertension. Drugs 1997; 54: 299-311.

14. Black HR, Bailey J, Zappe D, Samuel R. Valsartan: more than a decade of experience. Drugs 2009;69(17):2393-2414.

15. Pitt B, Poole-Wilson PA, Segal R et al . Effect of losartan compared with captopril on mortality in patients with symptomatic heart failure: randomised trial - the Losartan Heart Failure Survival Study ELITE II. Lancet 2000; 355:1582-1587.

16. Laeis P, Puchler K, Kirch W. The pharmacokinetic and metabolic profile of olmesartan medoxomil limits the risk of clinically relevant drug interaction. Journal of Hypertension. 2001;19:S21-S32

17. Oparil S, Dyke S, Harris F, Kief J, James D, Hester A, Fitzsimmons S. The efficacy and safety of valsartan compared with placebo in the treatment of patients with essential hypertension. Clin Ther 1996;18(5):797-810.

18. Oparil S, Dyke S, Harris F, Kief J, James D, Hester A, Fitzsimmons S. The efficacy and safety of valsartan compared with placebo in the treatment of patients with essential hypertension. Clin Ther 1996 Sep-Oct;18(5):797810.

19. Schaefer, F; Coppo, R; Kadwa, MY; Schlosshauer, R3; Zhang, Y. Efficacy and Safety of Valsartan in Hypertensive Children 6 Months To 5 Years of Age: A Randomized, Double-Blind, Dose-Response Study. Journal of Hypertension 2010; 28: 473 